
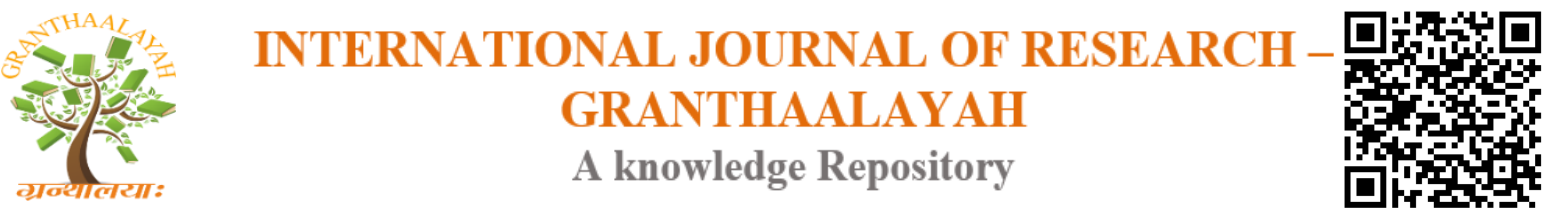

Science

\title{
FLEXURAL PROPERTIES OF WOOD SAWDUST AND OIL BEAN POD SHELL FILLED COMPOSITE
}

\author{
Nyorere Frank ${ }^{* 1}$, Emu Alfred ${ }^{2}$ \\ ${ }^{* 1}$ Department of Agricultural and Bio-Environmental Engineering Technology, Delta state \\ Polytechnic, Ozoro, Nigeria \\ ${ }^{2}$ Department of Mechanical Engineering Technology, Delta State Polytechnic, Ozoro, Nigeria
}

\begin{abstract}
Composites reinforced with natural materials play a vital role in engineering applications, like the fabrication of automobile parts, furniture making, etc. The objective of this present research is to determine the flexural properties (flexural strength, flexural energy) of oil bean pod shell (OBPS) and hardwood sawdust (SD) reinforced composite in epoxy matrix, at different filler loading. Hybridized composite samples used for this research were prepared with 20, 25, 30, 35, and 40\% filler (SD and OBPS in the ratio of 1:1) reinforcements in the ratio of 1:1. The flexural test was conducted on the samples according to ASTM D-790, using the Universal Testing Machine. From the results obtained, the fillers loading had significant $(\mathrm{P} \leq 0.05)$ effect on the three flexural properties studied. The flexural strength increased from 33.44 to $67.65 \mathrm{MPa}$, the flexural energy increased $53.1 \%$, while the flexural yield strength increased from 23.58 to $55.4 \mathrm{MPa}$. The results obtained from this research will be helpful the automobile and construction companies.
\end{abstract}

Keywords: Sawdust; Oil Bean Shell; Composites; Flexural Properties.

Cite This Article: Nyorere Frank, and Emu Alfred. (2018). "FLEXURAL PROPERTIES OF WOOD SAWDUST AND OIL BEAN POD SHELL FILLED COMPOSITE." International Journal of Research - Granthaalayah, 6(11), 337-344.

\section{Introduction}

A composites are produced by combining two or more materials with different together. The combined materials work together to give the composite unique properties. Natural composites are made from biomaterials (animals and plants) parts. Choosing appropriate combination of matrix and reinforcement material, a new material which exactly meets the requirements of a particular application, can be achieved (RSC, 2018). Natural materials are gaining progressive account, since they are renewable, environmentally friendly, and biodegradable. They are fast becoming starting material for industrial and civil engineering applications, such as; textiles, composites, pulp and paper, building components, etc. Natural fibres reinforced composites combine acceptable mechanical properties with a low density (Yang et al., 2004; Uguru and Uyeri, 2018). Mechanical properties of natural fibre reinforced composites are comparable to those of synthesis fibre 
reinforced composites. Therefore, they are often used to produce structural components like panels, doors, roofs and covers in the automotive industries (Uguru and Umurhurhu, 2018). Hybridization of two or more different materials can offers some advantages over using one material alone in a composite matrix. This is because hybrid composite materials offered a combination of strength and modulus that are either comparable to or better than many pure materials (Rowell, 1997). Natural fibre reinforced polymer matrix composites are very sensitive to influences from environmental agents such as water (Kumar et al., 2015). Composites are multifunctional material systems with qualities which are not obtainable from one separate material. Composites are cohesive structures made by combining two or more compatible materials together. The main advantage of composites over other materials is their natural ability to be custom tailored to a specific design situation. Materials like wood sawdust and matrix can be used in different combinations to acquire an optimal material composition (Nyior et al., 2018).

Natural materials contained a hydroxyl group due to cellulose and lignin. This group is involved in hydrogen bonding within the cellulose, thereby reducing their strength and matrix adhesion. Therefore, natural materials are treated to improve their mechanical properties, ageing and matrix adhesion (Edeerozey et al., 2007; Militky and Jabbar, 2015). The chemical treatment of the fibre has enhanced the adhesion between the fibre and the matrix and consequently it has improved the mechanical properties of the composites (Ismail et al., 2010). Cao et al., (2006) studied the effect alkaline treatment on the mechanical properties of bagasse fibre biodegradable composites and found that the mechanical properties of the treated composites were superior to the untreated composites. According to their results, the tensile strength of the treated composites increased by about $13 \%$, the flexural strength $14 \%$, while the impact strength $30 \%$.

Presently, there are many researches on the incorporation of wood sawdust and other natural materials as reinforcement into polymers. According to Rozman et al. (2001), there was a reduction of flexural and tensile strengths from the incorporation of oil palm empty fruit bunch (EFB) and glass fibre (GF) into polypropylene (PP) matrix. Kalam et al. (2005) found that increasing fibre volume ratio from $35 \%$ to $551 \%$ for oil palm fruit bunch fibre (OPFBF)/epoxy composite reduced the tensile strength of the composite and increased the Young's modulus. Composite of Arenga pinnata fibre reinforced epoxy showed that the $10 \mathrm{wt} \%$ woven roving fibre has the highest value of flexural strength test (Sastra et al. 2005). The mechanical properties of short random oil palm fibre reinforced epoxy (OPF/epoxy) composites were studied by Yusoff $e t$ al., (2010). Their results showed that the tensile and flexural properties of the composite showed inverse variation with fibre loading. Prosper and Uguru (2018), reported that the transverse rupture strength and the bending Modulus of wood Sawdust/Oil bean shell reinforced epoxy composites, increased up to $50 \%$ fillers reinforcement, and then decreases again after 50\%. This was attributed to weak adhesion of the fillers by the matrix at higher reinforcement percentages. Improving its flexural characteristics of composites made them useful in the development of materials with high performance characteristics (Kumar et al., 2015). Siddika and Sharif (2015) studied the hybrid fiber combination of Areca and Waste Nylon Fiber with Polypropylene (PP). Their results showed that the flexural and impact strength of the composites increases with increase in fibre percentage in the composite and later strength decreases with increase in fiber content. 
From the literature review, it is evident that no work has been done on the flexural performance of sawdust and oil bean pod shell reinforced composites. Therefore, the objective of this work is to study the flexural behaviour of wood sawdust and oil bean pod shell reinforced epoxy composites.

\section{Materials and Methods}

\subsection{Material Selection}

The Epoxy LY556 resin and HY951 hardener used to prepare the composite matrix were purchased from a chemical shop at Onitsha, Anambra state, Nigeria. The mahogany timber used to prepare the sawdust was obtained from a local wood contractor in Ozoro, Delta State, Nigeria. While the oil bean pod shells were collected from a Delta State Polytechnic Ozoro, Delta State, Nigeria

\subsection{Sample Preparation}

Preparation of the Oil Bean Pod Shell Particulate: The oil bean pod shells were washed to remove sand and other impurities. After the washing, the shells were sundried and ground to produce the particulate. The resulting particles were treated with $5 \% \mathrm{NaOH}$ for $1 \mathrm{~h}$, oven dried, and sieved with $150 \mu$ stainless steel sieve.

Hardwood Sawdust Preparation: The saw dust was treated with $5 \% \mathrm{NaOH}$ solution for $1 \mathrm{~h}$ at room temperature, and oven dried. A $150 \mu$ stainless steel sieved was used to sieve the resulting dried threated saw dust.

\subsection{Preparation of Hybrid Composite}

The composite board was prepared by hand lay-up technique. A mould of $200 \times 150 \times 5 \mathrm{~mm}^{3}$ made of wood, which was first applied with a very thin film of wax, to facilitates fast release of the composite was used for the casting of the composite board (Prosper and Uguru, 2018). The composites were made with 10,15,20,25, and 30\% reinforcements of wood sawdust and groundnut shell particulate in the ratio of 1:1, as shown in Table 1. The epoxy resin and hardener were mixed in the ratio of 70:30\% by weight. During the casting, measured quantities of wood sawdust, oil bean shell particulate and resin were poured into a container and stirred thoroughly for 30 min to obtain a homogeneous mixture. Then measured quantity of the hardener was added and the mixture was again stirred thoroughly for 20 minutes before it was poured into the already prepared mould. After the casting, the mould was kept under a load of $20 \mathrm{~kg}$ at room temperature for 24 hours to expel any entrapped air; after which, the composite board was detached from the mould. The composite board was then cured for 21 days at room temperature (Prosper and Uguru, 2018).

Table 1: The percentage composition of samples with varying proportions of matrix and filler

\begin{tabular}{|l|l|l|l|}
\hline Sample & EP (wt\%) & SD (wt \%) & OBPS (wt\%) \\
\hline S1 & 90 & 5 & 5 \\
\hline S2 & 85 & 7.5 & 7.5 \\
\hline
\end{tabular}




\begin{tabular}{|l|l|l|l|}
\hline S3 & 80 & 10 & 10 \\
\hline S4 & 75 & 12.5 & 12.5 \\
\hline S5 & 70 & 15 & 15 \\
\hline
\end{tabular}

\subsection{Flexural Test}

The flexural test was performed using a Universal Testing Machine (Testometric model), equipped with a microprocessor. The test was done in accordance with ASTM standard, using the 3-point bending fixture, utilizing centre loading on a simple supported beam (Prosper and Uguru, 2018). The following flexural parameters (Flexural strength and flexural energy), were generated by the microprocessor of the Universal Testing Machine. Flexural strength is the stress in the composite just before it yields in the flexure test (Ashby, 2011). Five samples were tested and the average values were recoded.

\subsection{Statistical Analysis}

The data obtained from this study were subjected to Analysis of variance using SPSS statistical software (version 20.0, SPSS Inc, Chicago, IL). The means separation was done by using the Duncan's multiple range tests at 95\% confidence level.

\section{Results and Discussion}

The Analysis of Variance (ANOVA) of the flexural parameters of the composites samples are presented in Table 2. As shown in Table 2, the filler loading rate had significant $(\mathrm{P} \leq 0.05)$ effect on all the flexural parameters studied in this research.

Table 2: ANOVA for response of flexural properties of hybrid composite to filler loading

\begin{tabular}{|l|l|l|l|}
\hline Source & df & F & Sig \\
\hline Flexural strength & 4 & 335.012 & $1.32 \mathrm{E}-10^{*}$ \\
\hline Flexural energy & 4 & 52.621 & $1.11 \mathrm{E}-06^{*}$ \\
\hline Yield strength & 4 & 67.849 & $3.29 \mathrm{E}-07^{*}$ \\
\hline BendStbk & 4 & 336.293 & $1.30 \mathrm{E}-10^{*}$ \\
\hline BeakingEn & 4 & 57.638 & $7.19 \mathrm{E}-07^{*}$ \\
\hline
\end{tabular}

* = Significant at $\mathrm{P} \leq 0.05, \mathrm{df}=$ degree of freedom.

Results of the flexural properties of the samples at various dispersed fillers concentrations fillers are presented in Figures 1 - 3. From Figures 1 to 3, it was found that the filler loading rate improved the flexural properties of the samples. Figure 1 showed that the flexural strength increased by 50.5, in addition, as shown in Figure 1, there was no significant difference between the flexural strength of samples 3 and 4. Furthermore, the experimental results presented in Figure 2, depicted a steady increment in the flexural energy of the composites with increased in fillers reinforcement, The flexural energy increased from $15.19 \mathrm{Nm}$ at $10 \%$ volume reinforcement to $32.44 \mathrm{Nm}$ at $20 \%$ volume reinforcement. According to Fu et al., (2008) the mechanical properties of particulatefilled polymer micro and nano- composites are affected by particle size, particle content and particle/matrix interfacial adhesion. 
Similar result was obtained by Kumar et al., (2015), where the flexural strength of composite samples was increased by $30 \%$ with addition of carbon fibre and sawdust. Kumar et al., (2012) in their research, showed a remarkable improvement in the flexural strength of composite samples at different concentration of the dispersed fillers. Reddy et al, (2015), reported that the tensile, flexural, and impact properties of Wollastonite reinforced filled epoxy were higher than those of unfilled epoxy. Myrtha et al. (2008) found out that the flexural strength of empty fruit bunch/polyester composites for longer fibre is $36.8 \mathrm{MPa}$ while for short fibre is $33.9 \mathrm{MPa}$ both at 18 volume percent. In addition, it was reported by Azis and Ansell (2004) that the flexural strength value of composite depended very much on fibre/filler alignment and the location of resin-rich areas. Weak fibre/matrix bonding contributes to poor flexural properties of composites materials (Khalil et al., 2007). The results of a study conducted by (Odera, 2014) on the flexural strength of raffia palm fibre-cement composites showed that, addition of raffia palm fibre to cement composites increases the flexural strength by more than $100 \%$ in comparison with the control, with zero per cent fibre volume fractions. The strength of hybrid particulate epoxy composites with various glass bead loading and different rubber content increases with the amount of glass beads (whose size varies from 3 to $70 \mu \mathrm{m}$ ) (Maazouz et al., 1993). These experimental results gotten from this research showed that, composites obtained by the hybridization of wood sawdust and oil bean pod shell can be used in used in various engineering applications, mostly were low stress is involved. Composites provide design flexibility; this is because since they are moulded, they can be produced into various complex sizes and shapes.

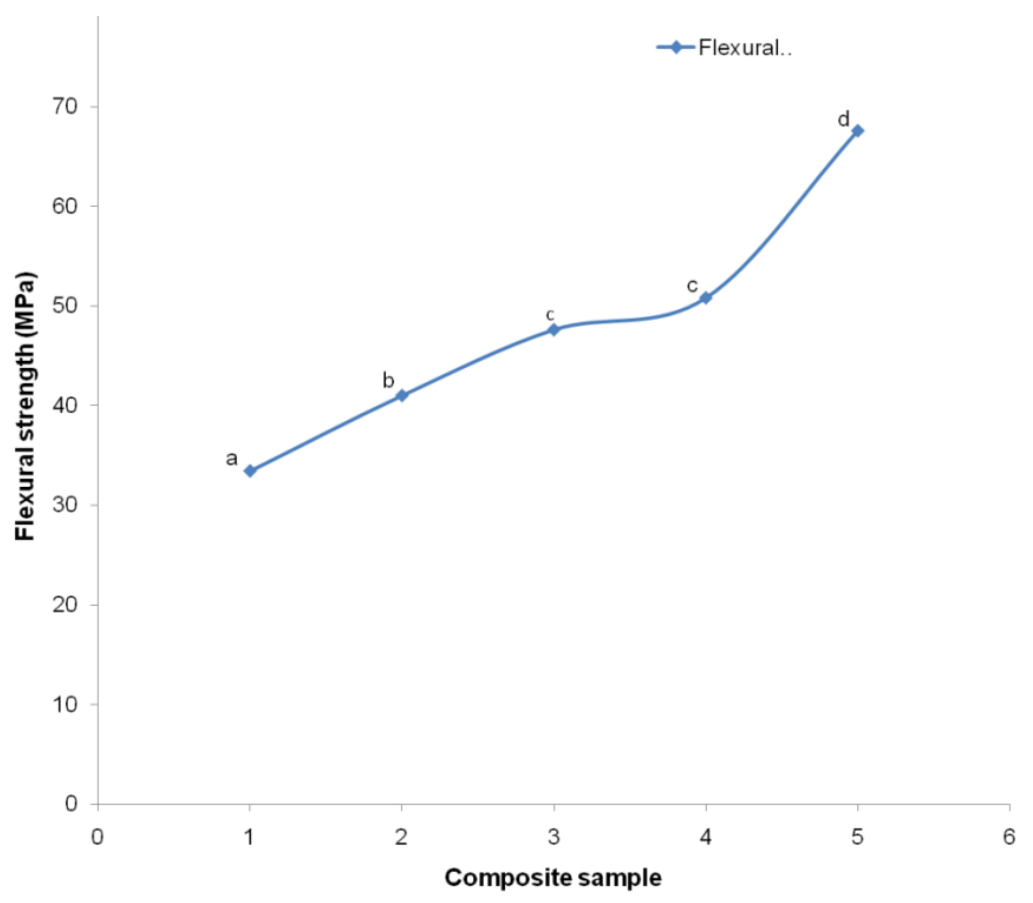

Points with the same common letters means that they are not significant different at $(\mathrm{P} \leq 0.05)$

Figure1: Effect of filler loading on the flexural strength of natural composite 


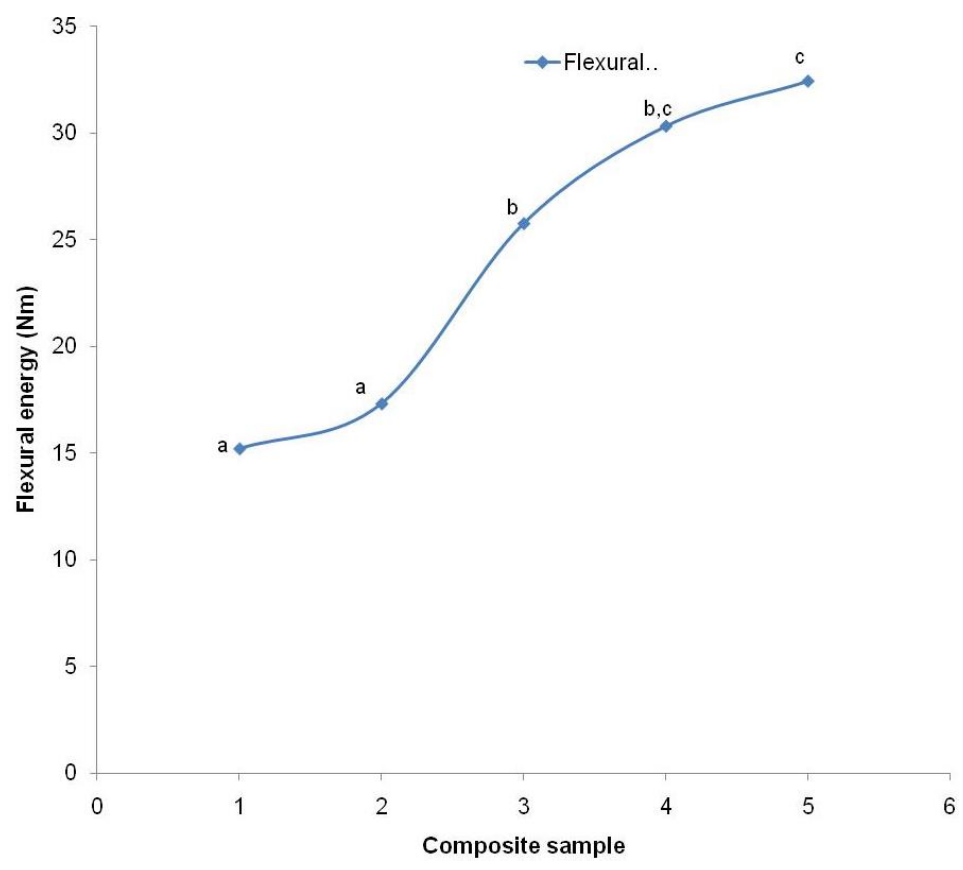

Points with the same common letters means that they are not significant different at $(\mathrm{P} \leq 0.05)$

Figure2: Effect of filler loading on the flexural energy of natural composite

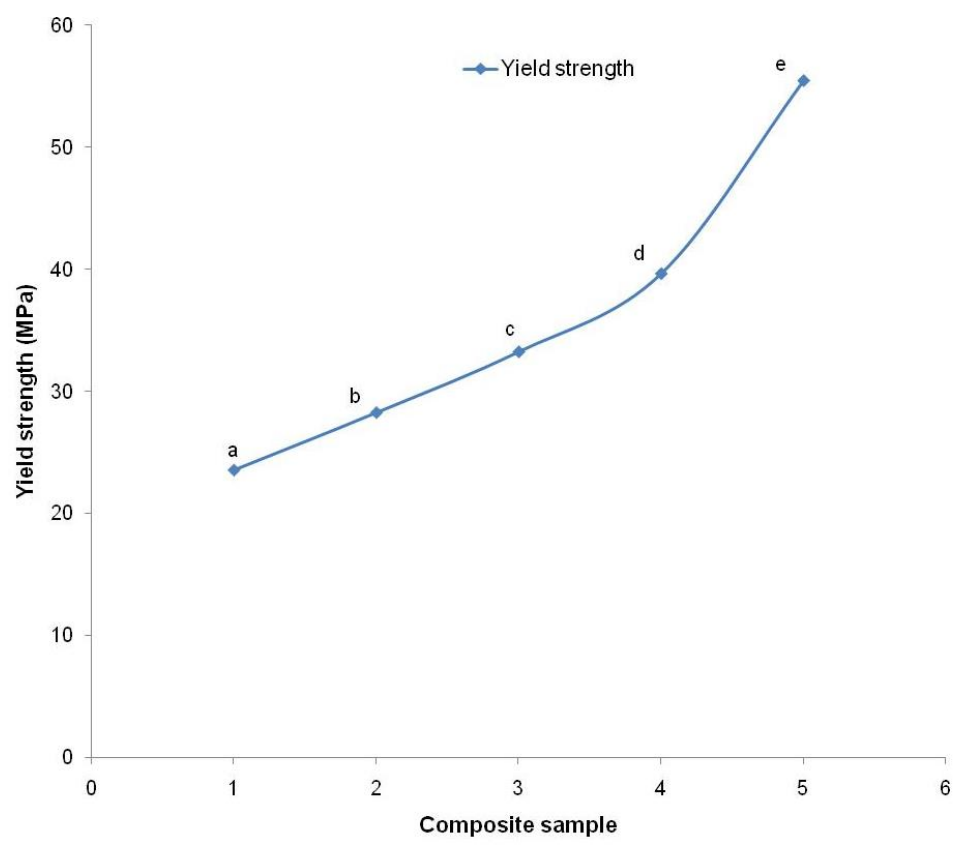

Points with the same common letters means that they are not significant different at $(\mathrm{P} \leq 0.05)$

Figure3: Effect of filler loading on the yield strength of natural composite

\section{Conclusions}

In this research, the flexural properties of hardwood sawdust and oil bean pod shell hybrid epoxy composites were investigated. The results obtained showed that the flexural strength, flexural energy and yield strength increased with the fillers loading. As the fillers loading increased from 10 to $30 \%$, the flexural strength increased from 33.44 to $67.65 \mathrm{MPa}$, the flexural energy increased 
$53.1 \%$, while the flexural yield strength increased from 23.58 to $55.4 \mathrm{MPa}$. With the increased environmental awareness about synthesis materials, engineers are increasing developing interest in the use of natural in various engineering applications.

\section{References}

[1] Ashby, M. (2011). Materials selection in mechanical design. Butterworth-Heinemann. p. 40.

[2] ASTM D 3039/D 3039M. Standard test method for tensile properties of polymer matrix composite materials. Annual book of ASTM standards, 8(1). Philadelphia (PA): American Society for Testing and Materials.

[3] Azis, S.H. and Ansell, M.P. (2004). The effect of alkalization and fibre alignment on the mechanical and thermal properties of kenaf and hemp bast fibre composite: Part 1- polyester resin matrix. Journal of Composite Science and Technology 64: 1219-1230.

[4] Cao, Y., Shibata, S. and Fukumoto, I. (2006). Mechanical properties of biodegradable composites reinforced with bagasse fibre before and after alkali treatments. Composites Part A-applied Science and Manufacturing, 37: 423-429.

[5] Edeerozey, A.M., Akil, H.M., Azhar, A. and Ariffin, M.I.Z (2007). Chemical modification of kenaf fibers. Mater Lett. 61: 2023-2025.

[6] Fu, S., Feng, X., Lauke, B. and Mai, Y. (2008) Effects of particle size, particle/matrix Interface adhesion and particle loading on mechanical properties of particulate- polymer composites. Composites Part B: Engineering, 39: 933-961.

[7] Ismail. H., Abdullah, A. H. and Bakar, A. A. (2010). The effects of a silane-based coupling agent on the properties of kenaf core-reinforced high-density polyethylene (HDPE)/soya powder composites. Technol. Eng. 49 (11): 1095-1100

[8] Kalam, A., Sahar, B.B., Khalis, Y.A. and Wong, S.V. (2005). Fatigue behaviour of oil palm fruit bunch fibre/epoxy and carbon fibre/epoxy composites. Composite Structure. 71: 34-44.

[9] Khalil, H.P.S.A., Issam, A.M., Ahmad, S.M.T., Suriani, R. and Awang, A.Y. (2007). Conventional agro - composites from chemically modified fibres. Industrial Crops and Products. 26: 315-323

[10] Kumar, N.A., Reddy, G,R,, Ramesh, A., Reddy, B.H., Mahesh, K.R. Kumar, P.V.S. (2012). Performance of coconut shell particulate filled polyester composites. Pakistan Journal of Scientific Industrial Research Ser-A, Phy. Sci. 55(3):142-148.

[11] Kumar, M.A., Chowdary, T.M., Balaji, K.C., Goud, E.D., Nagaraju, K. Ahmmed, S., and Sekhar, B.R. (2015). Effects of performance on mechanical properties of sawdust/carbon fibre reinforced polymer matrix hybrid composites. International Letters of Chemistry, Physics and Astronomy. 54:122-130

[12] Maazouz, A., Sautereau, H.and Gerard, J.F. (1993). Hybrid-particulate composites based on an epoxy matrix, a reactive rubber, and glass beads: morphology viscoelastic, and mechanical properties. J Appl Polym Sci. 50:615-26.

[13] Militky, J., and Jabbar, A. (2015). Comparative evaluation of fiber treatments on the creep behavior of jute/green epoxy composites. Compos Part B Eng. 80: 361-368.

[14] Myrtha, K., Holia, O., Dawam, A.A.H. and Anung, S. (2008). Effect of oil palm empty fruit bunch fibre on the physical and mechanical properties of fibre glass reinforced polyester resin. Journal of Biological Sciences 8(1): 101-106.

[15] Nyior, G.B., Aye, S.A. and Tile, S.E. (2018) Study of Mechanical Properties of Raffia Palm Fibre/ Groundnut Shell Reinforced Epoxy Hybrid Composites. Journal of Minerals and Materials Characterization and Engineering, 6: 179-192.

[16] Odera, R.S (2014). Optimization of the flexural strength of raffia palm fibre-cement composite. Journal of Engineering Trends in Engineering and Applied Sciences, 2: 294-297. 
[17] Prosper. O and Uguru, H. (2018). Effect of fillers loading on the mechanical properties of hardwood sawdust/oil bean shell reinforced epoxy hybrid composites. Int J S Res Sci. Engg. Tech. 4(8): 620626

[18] Reddy, G. R. Kumar, M.A., Ramesh, A., Basha, M., Karthikeyan, N. and Reddy, M, (2015). Preparation of glass fibre/ wollastonite reinforced epoxy hybrid composite: mechanical properties. Pakistan Journal of Scientific Industrial Research, Ser. A: Phys. Sci., 58 (1): 26-33.

[19] Rowell, R.M. (1997). Utilization of natural fibres in plastic composites, problems and opportunities. Journal of Thermoplastic Composites Materials, 15: 281-300

[20] Rozman, H.D., Tay, G.S., Kumar, R.N., Abusamah, A., Ismail, H. and Mohd Ishak, Z.A.M. (2001). Polypropylene - oil palm empty fruit bunch - glass fibre hybrid composites: a preliminary study on the flexural and tensile properties. European Polymer Journal 37: 1283-1291.

[21] RSC, (2018). Composite materials. Available at: http://www.rsc.org/Education/Teachers/Resources/Inspirational/resources/4.3.1.pdf

[22] Sastra, H.Y., Siregar, J.P., Sapuan, S.M., Leman, Z. and Hamdan, M.M. (2005). Flexural properties of Arenga pinnata fibre reinforced epoxy composites. American Journal of Applied Sciences. (Special Issue): 21-24

[23] Sgriccia N, Hawley M.C., and Misra, M. (2008). Characterization of natural fibre surfaces and natural fibre composites. Compos Part A - Appl Sci Manuf. 39(10):1632-1640

[24] Siddika, S. and Sharif, A. (2015). Processing and characterization of areca and waste nylon fiber reinforced hybrid polypropylene composites. International Journal of Innovation and Scientific Research. 19:319-330.

[25] Uguru, H. and Umurhurhu B. (2018). Effect of alkaline treatment on tensile properties of raffia palm fibre. Direct Research Journal of Engineering and Information Technology. 5 (4): 28-31

[26] Uguru, H. and Uyeri, C. (2018). Effect of vine section on the tensile properties of fluted pumpkin vine. Direct Research Journal of Engineering and Information Technology. 5(5): 10-16

[27] Yang, H.S., Kim, H.J., Son, J., Park, H.J. Lee, B.J. and Hwang, T.S. (2004). Rice-husk flour filled polypropylene composites; mechanical and morphological study. Composite Structures. 63 (3): 305-312.

[28] Yusoff, M.Z.M., Salit, M.S., Ismail, N. and Wirawan, R. (2010) Mechanical properties of short random oil palm fiber reinforced epoxy composites. Sains Malaysiana, 39, 87-92

*Corresponding author.

E-mail address: erobo2011@ gmail.com 